\title{
Recursos
}

\section{videoescénicos en}

la dramaturgia intermedial. Análisis

de The Mountain de Agrupación Señor Serrano

Videostaging resources in the intermedial dramaturgy. Analysis of The Mountain, by Agrupación Señor Serrano

José Manuel Teira Alcaraz

Ingeniero de telecomunicación por la UPCT, máster en estudios avanzados de teatro por la UNIR y máster en calidad en educación superior por la UOC. Doctorando en estudios teatrales en la UCM. Actor, locutor, técnico de calidad y docente. Investiga la dramaturgia de las interacciones del vídeo con el teatro y las poéticas de la incorporación de tecnologías a la escena. Contato: jteira@ucm.es Espanha 


\section{PALABRAS CLAVE:}

teatro multimedia, dramaturgia, videoescena, Agrupación Señor Serrano, teatro intermedia.

KEYWORDS: multimedia theatre, dramaturgy, videostage, Agrupación Señor Serrano, intermedial theatre.
Resumen: En el teatro contemporáneo la videoescena se ha consolidado en la plástica escénica como la integración de audiovisuales en escena con múltiples objetivos. Agrupación Señor Serrano es una compañía española que incorpora el vídeo a sus escenificaciones bajo la premisa de la intermedialidad, es decir, la puesta en escena se articula por medio de la hibridación entre teatro y audiovisual. Utiliza recursos de la cultura popular sumados a un ácido sentido crítico, que desarrolla a través de la simultaneidad, la yuxtaposición, la alternancia y los múltiples puntos de vista mostrados por la videoescena. Este artículo presenta un análisis de la intermedialidad de su espectáculo The Mountain (2020). Para ello se discriminan las funciones dramatúrgicas del vídeo, a fin de exponer cómo la inserción del audiovisual en la dramaturgia espectacular ensancha la teatralidad al crear una forma teatral a partir del permanente diálogo entre escena y videoescena.

Abstract: In contemporary theatre the videostage has consolidated in the stage plastics as the integration of audiovisuals on stage with multiple purposes. Agrupación Señor Serrano is a Spanish company which incorporates the video into its spectacles under the premise of intermediality, in other words, the mise-en-scène is articulated by means of hybridization of theatre and audiovisuals. It uses resources from the popular culture summed up to an acid critical sense which is developed through simultaneity, juxtaposition, alternance and multiple points of view shown by the videostage. This paper presents an analysis of the intermediality of its spectacle The Mountain (2020). To do so, the dramaturgical functions of the video are discriminated, in order to present how the insertion of audiovisuals in the spectacular dramaturgy enhances the theatricality by creating a theatrical form from the permanent dialogue between stage and videostage 


\section{INTRODUCCIÓN}

El vídeo se ha convertido en recurso habitual de la escena contemporánea, lo que ha consolidado su integración como elemento expresivo de la plástica escénica junto con la escenografía, la iluminación y el vestuario. La incorporación del medio audiovisual a la realización escénica implica la hibridación de su lenguaje —eminentemente cinematográfico- con el teatral, lo cual redunda en una teatralización de la tecnología, al incorporarla como medio para alcanzar un valor deseable (Iglesias Simón, 2006, 53). Este campo de diseño es ya comúnmente reconocido en castellano con el nombre de videoescena (Thenon, 2005, 85; Luna, 2016, 115; Martínez, 2018, 173), el cual, de la misma manera que el resto de los elementos visuales y sonoros de la escenificación, debe guardar consistencia dramatúrgica para que no se convierta en un añadido por deseo de mayor modernidad. Así es como la tecnología adquiere significación estética (Giannachi, 2004, 6).

La interacción de la videoescena con la escena «física» altera la percepción del espacio, el tiempo y la acción escénica, razón que determina el grado de implicación del vídeo en la dramaturgia y redunda en el objeto para el cual se plantea (Teira, 2020b, 298). Abre, pues, un campo de posibilidades desde la simple ilustración hasta un pleno diálogo semiótico entre medios donde la propuesta de sentido espectacular se sostenga sobre el audiovisual. Este caso de máxima integración es el del teatro intermedia, donde existe una correlación mutua entre medios (Kattenbelt, 2008, 20) que establece la base de la escenificación. 
La dramaturgia intermedial emerge gracias a creadores como la compañía española Agrupación Señor Serrano, cuyos espectáculos se basan en la teatralización del vídeo. Puesto que la intermedialidad implica la hibridación dramatúrgica de la acción escénica con el audiovisual, este trabajo analiza la dramaturgia de la videoescena en The Mountain de Agrupación Señor Serrano, estrenado en 2020. Para ello, describe las funciones con que el medio audiovisual se utiliza en la escenificación y los recursos que emplea, observando la interacción semántica escena-videoescena. Si bien el aparato metodológico y terminológico para el análisis de la videoescena apenas ha sido explorado, se expone un sistema de nomenclatura y clasificación como punto de partida. El objetivo que se busca es doble: evidenciar la integración dramatúrgica de la videoescena en la propuesta de Agrupación Señor Serrano, así como poner de manifiesto la viabilidad del método de análisis propuesto.

2. TeRMINOLOGíA Y METOdOLOGÍA: INTERACCIONES VIDEOESCÉNICAS Y FUNCIÓN DRAMATÚRGICA Entiendo que en todo teatro dramático o posdramático, con o sin texto fuente previo existe un núcleo de convicción dramática o propuesta de sentido que vertebra el espectáculo (Hormigón, 2002, 158) y que los diseños escénicos deben contribuir a su consecución a través de una estrategia estéticoestilística común (Martínez Valderas, 2017, 58), de la que derivan estéticoestilísticas concretas para la iluminación, la escenografía, la videoescena, etc. La videoescena puede utilizarse por distintos motivos, desde la mera sustitución a la hibridación intersemiótica que fundamenta la propuesta de 
sentido espectacular. En el primer caso sería pertinente hablar de teatro multimedia, término habitual para referirse a cualquier forma escénica que incorpore audiovisuales (Giesekam, 2007, 8). Sin embargo, conviene limitar este término a aquellos usos de la videoescena no consustanciales a la forma espectacular (un personaje concreto, un elemento escenográfico, una atmósfera), lo que me lleva a distinguirlo del teatro intermedia, en el que Kattenbelt $(2008,25)$ destaca la «mutua influencia entre medios»: el medio audiovisual es constitutivo de la estrategia estético-estilística del espectáculo, que solo es viable por medio de él.

Sin embargo, considerar multimedia e intermedia como compartimentos estancos presenta limitaciones, ya que unos recursos videoescénicos tienen una tendencia más a lo multimedial y otros a lo intermedial, según el grado de incorporación del vídeo. Por tanto, como advierte Giesekam (2007, 9), es más práctico tomarlos como extremos de un segmento continuo. En él se pueden discernir las funciones dramatúrgicas del audiovisual en teatro.

El valor de la caracterización de la videoescena radica en favorecer el análisis de la función para la cual se utiliza y determinar su contribución a la dramaturgia de la escenificación (Teira, 2020a, 156). Un primer paso es detectar la preeminencia de espacio, tiempo y acción en escena o videoescena, respectivamente, o la búsqueda de simultaneidad entre ambas, a partir de lo cual describir su contribución. Para ello conviene considerar los dos posibles efectos que puede producir el audiovisual en teatro según López Antuñano (2012, 175): la ampliación metafórica y el zapping. El primero es una intersección que contribuye a la posibilidad de síntesis por el espectador, por 
ejemplo, una textura escenográfica en vídeo. El zapping o fragmentación supone la aparición de dos o más fragmentos no conectados linealmente y a menudo autorreferenciales, cuya recepción es sensorial y provoca la asociación inconsciente.

Para el análisis de la dramaturgia de la videoescena empleo la clasificación propuesta en Teira (2020b: 302), basada en cuatro categorías: videoescenografía, para funciones asimilables a la escenografía en su carácter espacial, locativo y atmosférico; videoescena multiplicativa cuando su función principal es fractal; videoescena caracterizadora para la creación, duplicación o modificación de personajes; y videoescena textual para la narración con texto. En cada una de ellas se distinguen casos que, por operatividad, son descritos conforme se identifican en The Mountain. Cada uno se estudia en cuanto a espacio, tiempo y acción y caracterizado como ampliación metafórica o fragmentación.

\section{Contextualización: la compañía y el espectáculo}

\subsection{Agrupación Señor Serrano}

Àlex Serrano fundó Señor Serrano en Barcelona en 2006 y pronto como Agrupación sumó a Pau Palacios y a Bárbara Bloin. Los tres forman el núcleo de la compañía que cuenta además con colaboradores, varios de ellos habituales. Su poética se desarrolla en tres escalas. La menor es la de la miniatura: pequeños muñecos, maquetas, tarjetas y objetos similares. En la escala intermedia los performers manipulan la anterior y realizan acciones 
Recursos videoescénicos en la dramaturgia intermedial. Análisis de The Mountain de Agrupación Señor Serrano

escénicas. La escala mayor es la de la videoescena, que engloba a las otras, haciendo perceptible la primera al tiempo que potencia la segunda y así es totalizadora de la dramaturgia intermedial.

La compañía escenifica espectáculos de creación propia con dramaturgia eminentemente visual basada en la videoescena, para lo cual recurre a herramientas tecnológicas y al lenguaje cinematográfico. Ellos lo denominan cine en tiempo real (MandragoraBCN, 2016), coincidiendo con el concepto de live cinema que utiliza en su creación intermedial la directora británica Katie Mitchell (59 Productions, 2014; Magris, 2016, 186). Se puede considerar su integración de la tecnología digital como tecnoteatro según los define Grande $(2015,10)$, fruto de «la producción del mundo como imagen» contemporánea. También se pueden encuadrar en el teatro visual, cuya narrativa se basa en la visualidad a la que «incorporar a su vocabulario escénico lenguajes provenientes de todos los campos de las artes visuales y de la comunicación» (Abellán, 2006, 107).

Ellos mismos reconocen dos etapas creativas (Teatro a mil, 2018); la primera hasta Memo (2010), con acción escénica, objetos y vídeo, que no era aún esencial, y una segunda desde Katastrophe (2011), donde las miniaturas ganan protagonismo, la acción escénica se limita y el vídeo se vuelve consustancial a la puesta en escena. Distingo también una tercera a partir de Kingdom (2018) y deudora de la anterior, que evoluciona hacia ensanchar el formato, profundizar en la dramaturgia del vídeo y recuperar la acción escénica. Preguntado por ello en Teira (2020c, 473), Pau Palacios 
reconoce cambios significativos a partir de Kingdom que permanecen en la compañía y se observan en The Mountain.

Serrano y Palacios suelen actuar como performers, manipuladores de objetos y operadores de cámara. Junto a ellos es habitual la presencia de otros performers y un técnico, de modo que toda la composición del espectáculo se haga a vista del público, en la línea del teatro de la presentación descrito por López Antuñano (2014, 180), donde hay ejecución, pero no interpretación, desjerarquización y multiplicidad.

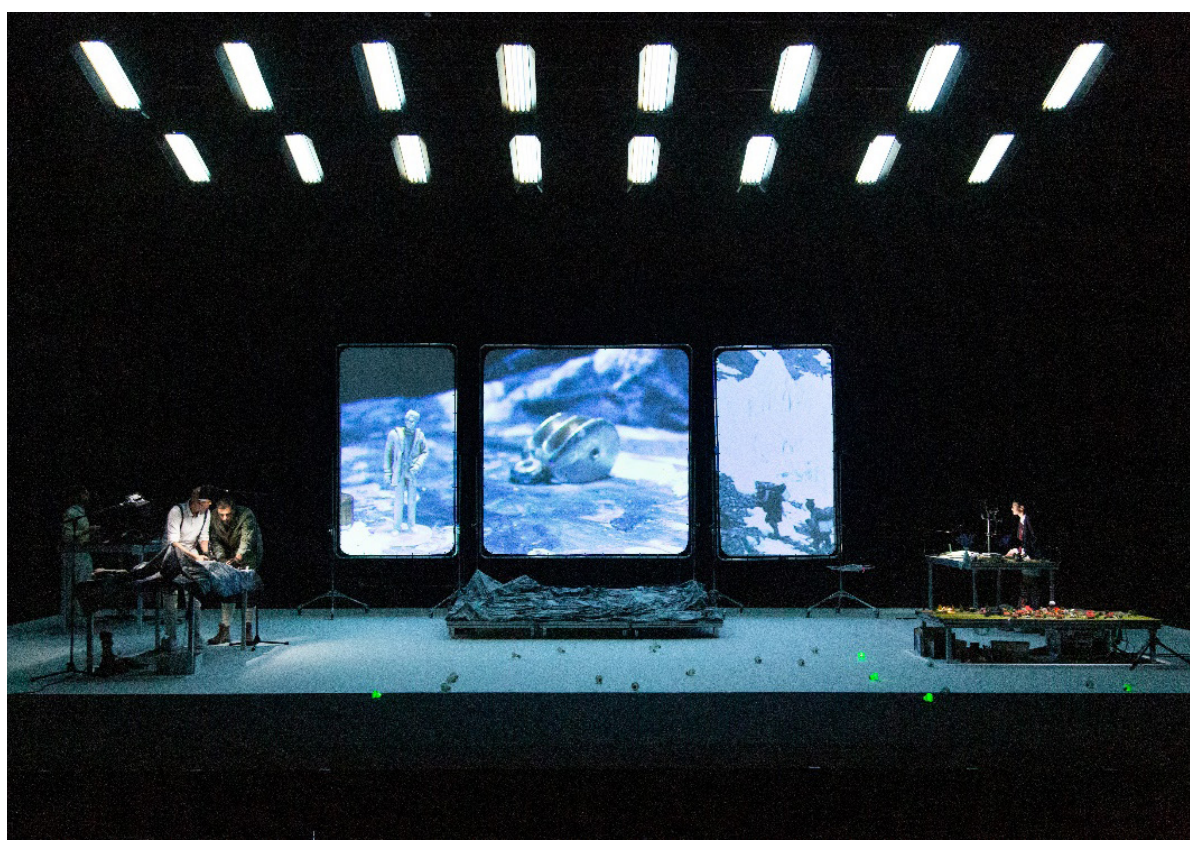

Figura 1: Un instante de The Mountain que muestra la multiplicidad y la presentación de los medios de creación.

Fuente: srserrano.com. Autoría: Jordi Soler. 
El proceso creativo de la compañía se inicia con una fase de investigación a partir de la cual se realizan iteraciones de dramaturgia y creación a lo largo de hasta tres residencias artísticas. A su término presentan un work in progress, cada cual de mayor duración, hasta dar su forma final al espectáculo, aunque lo consideran siempre abierto a modificaciones (Teatro a mil, 2018), en la línea de creadores como Robert Lepage (Iglesias Simón, 2005, 77).

El objetivo de las escenificaciones es la crítica social, realizada con humor mordaz. El vídeo permite mostrar múltiples puntos de vista, ampliar la escena y realizar insertos en una narrativa fractal a la que favorece. Como indica Lehmann $(2013,161)$ : «dramaturgia visual no solo significa una dramaturgia exclusivamente organizada visualmente, sino una dramaturgia que no se subordina al texto y puede desplegar libremente su propia lógica». Desde la imagen, las piezas de Agrupación Señor Serrano plantean varias líneas narrativas discontinuas en torno a un tema principal.

\subsection{The Mountain}

The Mountain (2020) ensambla la conquista del Everest con la versión radiofónica de La guerra de los mundos de Orson Welles en una crítica a aquello que asumimos como verdad, ejemplificada en una web ficticia de fake news y con el bádminton como conector. Es el duodécimo espectáculo de Agrupación Señor Serrano, aunque podría considerarse el undécimo de dramaturgia autónoma, ya que el anterior, Garden Center Europa (2019) se 
crea sobre la Novena Sinfonía de Beethoven interpretada por una orquesta sinfónica. Por eso, podría considerarse The Mountain como sucesor de Kingdom (2018) en cuanto a planteamiento temático y recursos escénicos. La cronología es interesante porque, como sus directores reconocen, cada espectáculo pasa algo al siguiente, tanto a nivel de contenido como de herramientas. Las similitudes formales de The Mountain con Kingdom son varias, entre las que pueden mencionarse el comienzo con un monólogo a público y el plano detalle de pequeños elementos para presentar en videoescena un entorno aparentemente mayor: en Kingdom la jungla costarricense y en The Mountain las nieves del Everest.

El inicio del confinamiento por la pandemia de covid-19 en marzo de 2020 coincidió con el regreso de la compañía de su última residencia de creación. Por esta razón, el espectáculo estaba avanzado, pero no había concluido para el que iba a ser su estreno en el Festival Grec de Barcelona en julio, motivo por el cual fue considerado por la Agrupación como preestreno. Así, hubo modificaciones hasta su estreno oficial en octubre en el Festival International des Arts Bordeaux Métropole.

Cuatro personas actúan como performers y manipuladores. Una de ellas, Anna Pérez Moya, desempeńa la mayor parte de la acción escénica. Otra, David Muñiz, es el técnico de sonido, vídeo y luces y controla un dron en escena. Las otras dos son Palacios y Serrano, que realizan sobre todo la manipulación de objetos y su captura en cámara. Reciben proyecciones tres pantallas, por primera vez móviles, lo cual dinamiza la presentación de la videoescena. Junto a ellas se disponen los espacios de manipulación. 
A la izquierda está la mesa técnica y en su perpendicular una primera mesa de objetos. Bajo la pantalla central hay una maqueta montañosa a ras de suelo. A la derecha hay otra mesa más baja con maquetas y otra detrás de la pantalla. La simetría del espectáculo es prácticamente constante.

En torno al tercer cuarto de todos sus espectáculos — que duran en torno a una hora-, Agrupación Señor Serrano incluye un recurso dramatúrgico que genera un corte impactante, una pausa en toda la narración. Su fin es afectar al espectador, limpiar todo para dar paso al auténtico «descenso a los infiernos» en palabras de Pau Palacios (Teira, 2020c, 479). En The Mountain no implica la videoescena. Palacios sale con una especie de máquina de nieve con la que, a través de un tubo y en el centro del escenario, hace «nevar» suavemente virutas blancas de papel sobre el escenario mientras es observado por el resto de los actantes. La hermosa y calmada imagen permite aliviar la reflexión previa para después impactarle con el discurso final.

\section{Análisis dramatúrgico de la Videoescena en The Mountain}

Como en Kingdom, el comienzo no incluye vídeo, algo inusual en los espectáculos de Señor Serrano. Mientras el público entra en la sala, los cuatro actantes están jugando al bádminton, con una pantalla como red, es decir, no se están viendo entre sí. Cuando el cambio de luz anuncia el comienzo, Anna Pérez Moya hace la introducción con un familiar discurso sobre lo que consideramos cierto que ejemplifica con la duda de si el desaparecido explorador George Mallory pudiera haber alcanzado 
la cima del Everest treinta años antes de su conquista oficial. Afirma estar jugando al béisbol mientras sostiene la raqueta de bádminton, así, cuestiona qué hace al béisbol o al bádminton ser tales. Entonces afirma que si todos los presentes así lo acuerdan ella puede estar jugando al béisbol y ser Vladimir Putin. Así es como con distorsión de voz Putin se convierte en el maestro de ceremonias.

El título del espectáculo, que aparece en vídeo después del prólogo, parte de una montańa en un cuadro de una maqueta. Se cierra sobre él el plano hasta fundirse con una imagen de los años 50 del famoso logo montańoso de Paramount Pictures, sin incluir el nombre del estudio, y luego transita a la animación del logo actual, donde aparece el título The Mountain. El fundido y transición resultan reveladores del paso del tiempo, desde su aparición clásica a la actual, como si siempre hubiese una montańa que subir. Montaña que, por cierto, no es el Everest, aunque su alusión es obvia por la narrativa, sino que, según es comúnmente aceptado, la montaña del logo de Paramount es el monte Artesonraju en Perú.

\subsection{Doble videoescénico mediante realidad aumentada}

La realidad aumentada es un elemento videoescénico nuevo en la poética de Agrupación Seńor Serrano. La cámara captura a la performer en directo, es mostrada en la pantalla central y un software de reconocimiento de imagen le superpone la cara del presidente ruso Vladimir Putin a la vez que un procesador de voz distorsiona su tono. Se trata de un uso intermedial, 
imposible de emular sin utilizar el vídeo y el software para mediar la acción, que funciona por zapping, por fragmentación en este caso de la acción y el espacio, al generar la copia virtual distorsionada.

La duplicación entre quien actúa y su doble videoescénico es un híbrido de dos recursos usuales de la dramaturgia de la videoescena: la réplica de acciones y el doble distorsionado. En Brickman Brando Bubble Boom (2012) el performer Diego Anido copia en escena las acciones de Marlon Brando en vídeo, algo utilizado por otras compañías como The Wooster Group en su Hamlet (2006) donde los actores recreaban la función de los años 60 proyectada de fondo. Esto implica una remediación por cuanto hay una réplica escénica del vídeo, esto es, un medio recrea a otro (Bolter y Grusin, 2000, 45). En The Mountain sucede a la inversa, el vídeo remedia la escena, haciendo que el directo dialogue con el vivo. Por su parte, el doble distorsionado duplica al actante alterando su imagen o la de su réplica, lo que produce una despersonalización que cuestiona la identidad del original, al tiempo que evidencia la corporeidad de la performer cuya «imagen proyectada carece de realidad más allá de un juego de luces y sombras» (Cornago, 2004, 600). Como dice Pavis (2000, 60) la coexistencia de cuerpo real y virtual hace estar «tan presente como ausente». Se invita al espectador a la reflexión sobre las relaciones entre original en escena y copia videoescénica. La realidad aumentada, a pesar de ser evidente en las formas y texturas de Putin, recuerda al recientemente popularizado deepfake, con el cual se superpone una cara de una persona sobre otra mediante reconocimiento de patrones realizado con aprendizaje 
máquina — una técnica de inteligencia artificial para la autoevolución del comportamiento de un sistema a partir de la información que recibe a la entrada pero sin estar programada a priori_-, lo cual genera resultados sorprendentemente realistas y que, de hecho, son ejemplificados en una breve secuencia de la cara del técnico David Muñiz sobre Tom Cruise en la película La guerra de los mundos (2005).

El distanciamiento entre original y copia se acrecienta si la posición de ambos difiere. Sucede cuando, tras un texto sobre las fake news, aparece la performer de perfil con su cara siendo recogida por el dron y proyectada sobre la pantalla central con la máscara de realidad aumentada de Putin superpuesta, lo que provoca un mayor pluriperspectivismo.

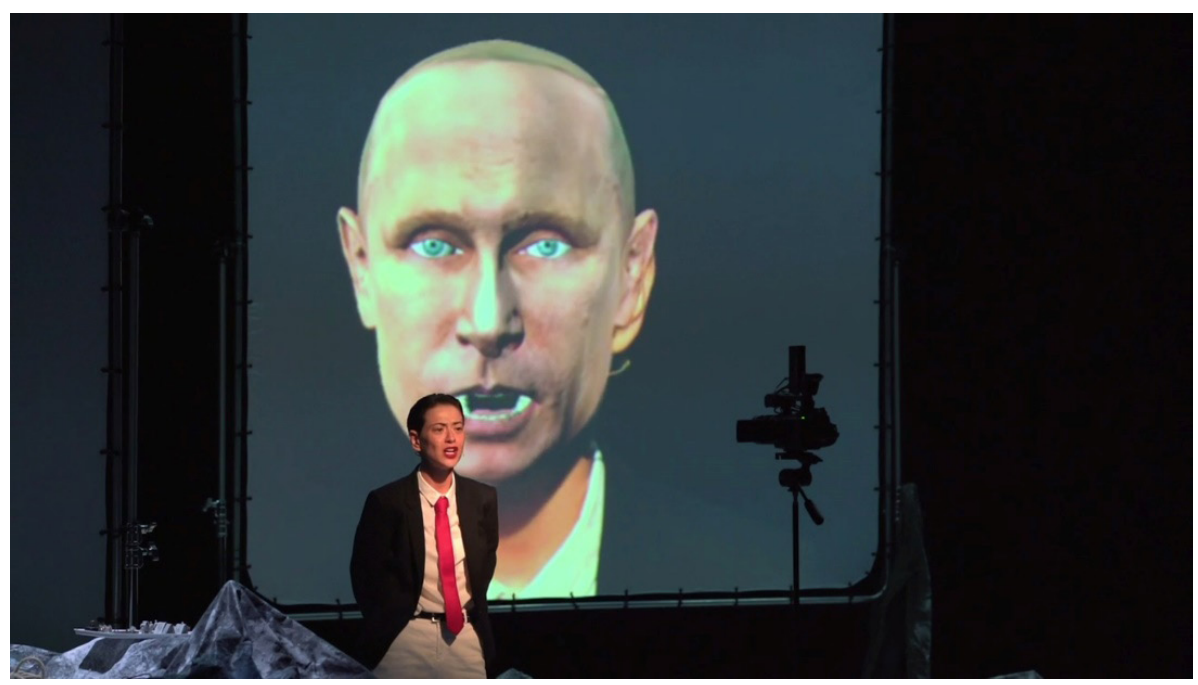

Figura 2: Putin como doble distorsionado de la performer mediante realidad aumentada.

Fuente: Agrupación Señor Serrano. 
El recurso es llevado al extremo cuando muestra que el Putin videoescénico no depende del soporte de Anna Pérez Moya, sino que en un momento dado se intercambia con Pau Palacios frente al dron que los está registrando, y mientras ella sigue hablando mirando a proscenio, basta con que el performer mueva la boca para que el Putin de realidad aumentada lo haga y parezca que es él quien habla. El desdoblamiento en este caso es triple: la performer que actúa, el que simula actuar y su doble digital, que emula al primero, pero en realidad replica al segundo. Puesto que esto tiene lugar durante un discurso sobre la fiabilidad de las noticias y la confianza en ciertos medios de comunicación, la crítica a la verdad asumida se construye también desde la forma además del contenido.

\subsection{Ampliación de visibilidad con multiplicidad de puntos de vista}

La ampliación de la visibilidad es la función dramatúrgica de la videoescena más recurrente de Agrupación Señor Serrano, y en gran medida supone la base de su poética de escalas, ya que implica la grabación y reproducción en directo de objetos manipulados en escena cuyas composiciones visuales son asimilables a planos de cine. Al comienzo del espectáculo, la pantalla central recoge la imagen capturada por la cámara de Àlex Serrano en escena: un plano detalle continuo de elementos que rodean el cuerpo inmóvil de Pau Palacios como cadáver helado de Mallory. Aunque el público puede ver al performer acostado y cubierto de nieve, es la cámara al recorrer sus recovecos lo que activa la situación y permite discernir en videoescena detalles que 
desde el patio de butacas serían inaccesibles, a la vez que escoge el itinerario de atención y el zum con el que lo presenta. Se fusiona, por tanto, el lenguaje audiovisual con el escénico: si bien el espacio-tiempo y la acción escénicos son estáticos, cobran dinamismo a partir de la propuesta que hace la cámara y la edición en directo, pues se genera un punto de vista subjetivo que se desplaza. Se crea un escenario-plató que acoge una doble representación (López Antuñano, 2011, 142). La escena física y la escena mediada entablan un diálogo multiplicador del sentido cuya función es dual: se amplía la visibilidad de una imagen a la que el público solo podría acceder de manera general. Esto funciona por ampliación metafórica, pero al mismo tiempo ofrece una nueva perspectiva, que resulta fragmentaria. La videoescena genera un universo autónomo a partir del material escénico.

Un poco más tarde, como ya hiciera en Birdie (2016), la compañía despliega un elegante prólogo al recorrer el detalle de algunos objetos que contextualizan la narración espectacular, como un micrófono de radio antiguo, un guion de La guerra de los mundos, ilustraciones de un periódico o un paquete de tabaco. El más aparentemente descontextualizado es la pluma de bádminton, que enlaza con la acción inicial y que vuelve a aparecer después.

Acompañado del sonido de la retransmisión del programa de radio, el plano detalle transita a la miniatura de una casa americana de los ańos 30 y otras escenas que se van componiendo mediante recortables con las usuales imágenes promocionales de la época con colores saturados y la aparición de marcas como Coca-Cola o Texaco. Un guiño cinéfilo es la aparición en una pared de la montaña de Encuentros en la tercera fase (1977), lugar en torno al que se produce 
Recursos videoescénicos en la dramaturgia intermedial. Análisis de The Mountain de Agrupación Señor Serrano

el encuentro con los extraterrestres en dicha película. Otra referencia a ella es el sonido de las cinco notas características de su tema musical compuesto por John Williams, símbolo además de la comunicación entre la humanidad y los alienígenas. La referencia se repite en varias ocasiones.

Cuando la cámara realiza su composición cinematográfica, el medio audiovisual permite incluir los recursos que le son propios, como la música, la voz en off e incluso los efectos especiales. El tono histórico del viaje al Everest en The Mountain lleva a acompañar algunas secuencias con una voz en off de la supuesta amada de Mallory, quien recibía cartas de este a lo largo del viaje, mientras que en el ataque de La guerra de los mundos el sonido que acompaña es el propio programa de radio.

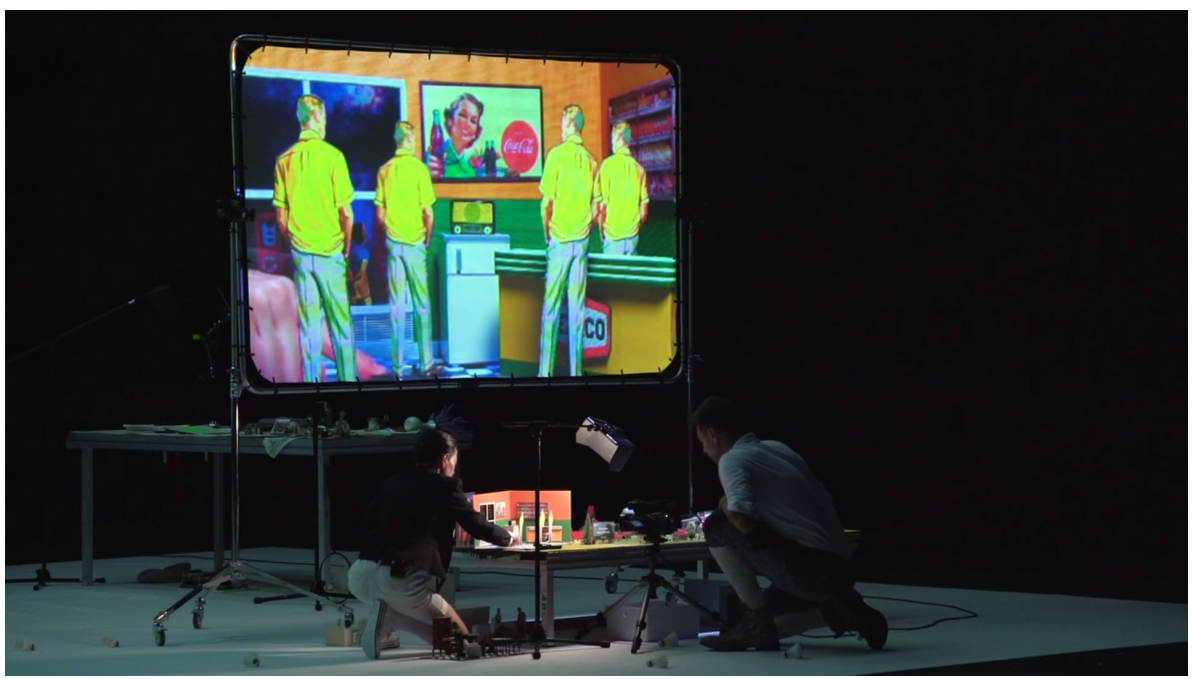

Figura 3: Palacios y Pérez Moya manipulan y capturan la maqueta de estilo años 30 en torno a la radio. Fuente: Agrupación Señor Serrano. 


\subsection{Inserto cinematográfico y yuxtaposición}

Agrupación Señor Serrano habitúa a incluir en sus espectáculos insertos de cine relacionados directa o indirectamente con la escena. El principal material que aparece The Mountain es Orson Welles hablando de su versión radiofónica de La guerra de los mundos de H. G. Wells en 1938, primero el Welles de años más tarde explicando el efecto que buscaban conseguir entre los oyentes, tratando de dar el máximo realismo y, al final del espectáculo, el Welles de entonces, justificando su ingenuidad ante la inesperada crisis causada por el programa. «¿A qué Orson Welles creemos?» pregunta entonces al público Anna Pérez Moya.

El inserto documental es un recurso de yuxtaposición clásico del teatro multimedia, desde Méliès a Svoboda, pasando por Meyerhold, Brecht y, en especial, Piscator, primer creador que se planteó dar sentido dramatúrgico a la imagen cinematográfica explorando la tensión provocada con la acción dramática (Piscator, 1976, 82). Funciona por fragmentación al incluir un elemento ajeno, quizá por ello no siempre se simultanea con acción.

Un elemento presentado a continuación de otro no tiene por qué guardar una relación de causalidad en el teatro posdramático, como no lo hace en la dramaturgia fractal de Agrupación Señor Serrano, donde es habitual que, sobre todo a través de la videoescena, se muestren imágenes de diferentes procedencias. En ellas el único elemento de continuidad puede ser la voz en off o la música, aunque tampoco deben guardar relación directa con lo mostrado. El espectador es quien establece las asociaciones y arguye un significado a partir de los estímulos que recibe. Hay una secuencia de 
insertos videoescénicos procedentes de diferente material cinematográfico. Primero vemos las tres pantallas con ruido, entonces de derecha a izquierda van mostrando una escena de Tom Cruise en la versión cinematográfica de 2005 de La guerra de los mundos. La música que la acompaña es la de un coro orante multitudinario reunido en torno a la Torre del Diablo en Encuentros en la tercera fase, escena a la que pasa precisamente después. Con un salto momentáneo al Putin de realidad aumentada, luego vemos a jugadores de bádminton junto con más fotogramas de Encuentros al tiempo que la música coral continúa. Un siguiente inserto es de Moisés en Los diez mandamientos frente a la zarza ardiente y un nuevo corte a La guerra de los mundos que cierra esta sucesión. Todos los insertos elegidos tienen que ver con el descubrimiento de la verdad, relacionado mitológicamente con el ascenso a la montańa, y la fe en lo recibido desde el cielo que, mientras que en Encuentros en la tercera fase es bueno para la humanidad, no lo es en La guerra de los mundos.

\subsection{Metavideoescena}

Un nuevo vídeo dentro de la videoescena que realiza una ampliación metafórica del primero. Se produce así una hiperinmediación (Teira, 2020b, 312) cuando se produce una evidencia del marco de la videoescena, mientras que la producción de la metavideoescena queda diluida en el entorno ficcional audiovisual. El término surge de los opuestos hipermediación como muestra del mecanismo tecnológico de imagen y 
la inmediación como difusión del mismo, según Abuín $(2008$, 36). La primera imagen funciona por hipermediación, mientras que la segunda es una inmediación dentro de la primera. En otros espectáculos puede aparecer como una televisión o una ventana de la maqueta tras la que se introduce el metavídeo. También se puede insertar sobre un elemento esperablemente estático, como un cuadro o una fotografía de periódico. En el primer tercio de The Mountain, un periódico recoge la llegada de Mallory a Darjeeling. En lugar de la típica fotografía ilustrativa, el croma permite a la videoescena insertar un vídeo. Así, se dinamiza el medio textual - o se textualiza el medio audiovisual -, al codificar una mutua influencia entre las características de ambos medios de comunicación.

El vídeo dentro del vídeo puede aparecer a la inversa, como sucede tras una sucesión de insertos cinematográficos sobre cuya última imagen se corre la cortina que se ubica en una de las pantallas. Se encadena, por tanto, el material videográfico con el material físicamente presente en escena, también empleando un croma.

\subsection{Simultaneidad}

El uso de tres pantallas favorece la presentación simultánea de elementos. Imágenes diferentes y de distinto origen en cada pantalla obligan al espectador a cambiar su foco de atención y asimilar la información simultánea, por dispar que sea. Esto fragmenta los puntos de vista del receptor en diversos discursos (Hartwing, 2004, 51). Fue una investigación de Svoboda desde 
1958 con su polipantalla, para buscar libertad de creación de imágenes múltiples, algo que consideraba propio del teatro (Burian, 1970, 133). Así, la simultaneidad de imágenes funciona por zapping en el espacio, igual que su sucesión lo hace en el tiempo.

Al principio del espectáculo aparece ruido blanco en una pantalla, después en una segunda y por último en la tercera, incluyendo el parpadeo del texto «no signal» y el sonido de una transmisión entrecortada. Después comienza la imagen de cámara en el centro mientras los laterales mantienen el ruido blanco, luego se suma a la ampliación de visibilidad la función de simultaneidad. Al ser una imagen ruidosa y no definida, no es la función principal, como sí lo es en otros momentos del espectáculo en los que cada pantalla tiene un contenido dramatúrgico; en este caso genera un marco contextual a la imagen central. Este ruido blanco presenta una doble lectura posible. En primer lugar, el evidente de ser una transmisión sin contenido, defectuosa o interrumpida, que se corta para encontrar el cadáver de Mallory, por lo cual se puede ver como una llegada de información que reconecta tras un largo silencio. Por otro lado, el ruido de imagen también es llamado en castellano «nieve», lo que entabla otra conexión con el Everest y el cuerpo congelado. Dicha identificación queda explicitada al final del espectáculo, cuando de la nieve sobre la mano de George Mallory se funde a nieve electrónica en una proyección que cubre toda la escena.

También se utiliza la simultaneidad puntual como transición, como al principio, cuando Orson Welles aparece en la pantalla central y en la 
izquierda se va enfocando un micrófono. Ambas imágenes perviven unos segundos hasta que se apaga el centro y la izquierda comienza su recorrido. En otro momento, el plano acaba con el muńeco de Mallory mirando al Everest en la pantalla central y aparece en la pantalla derecha una radio, que permanece mientras que la central pasa a Welles. La radio ha servido como conector.

En el plano siguiente se recorre la maqueta de la derecha donde aparece el pueblo Grover's Mill, donde se ubica La guerra de los mundos, a partir de su cartel de bienvenida, que incluye nuevamente el guiño a Encuentros en la tercera fase al representar la Torre del Diablo, montaña de Wyoming que aparece en dicha película. En su recorrido por el pueblo mientras suena el ficticio ataque alienígena radiado, se ve una pelota de bádminton, como si fuera un ser extraterrestre, haciendo de enlace con este elemento. El plano concluye con el dron, haciéndolo parecer una nave alienígena que mira a cámara. Mientras esto aparece en la pantalla derecha, la pantalla central muestra lo captado por el dron: a Serrano y Palacios observándola desde la mesa de manipulación de las miniaturas. Hay, por tanto, una simultaneidad entre observador y observado, como cuando la cámara enfoca a público y se ve en la pantalla central. 
Recursos videoescénicos en la dramaturgia intermedial. Análisis de The Mountain de Agrupación Señor Serrano

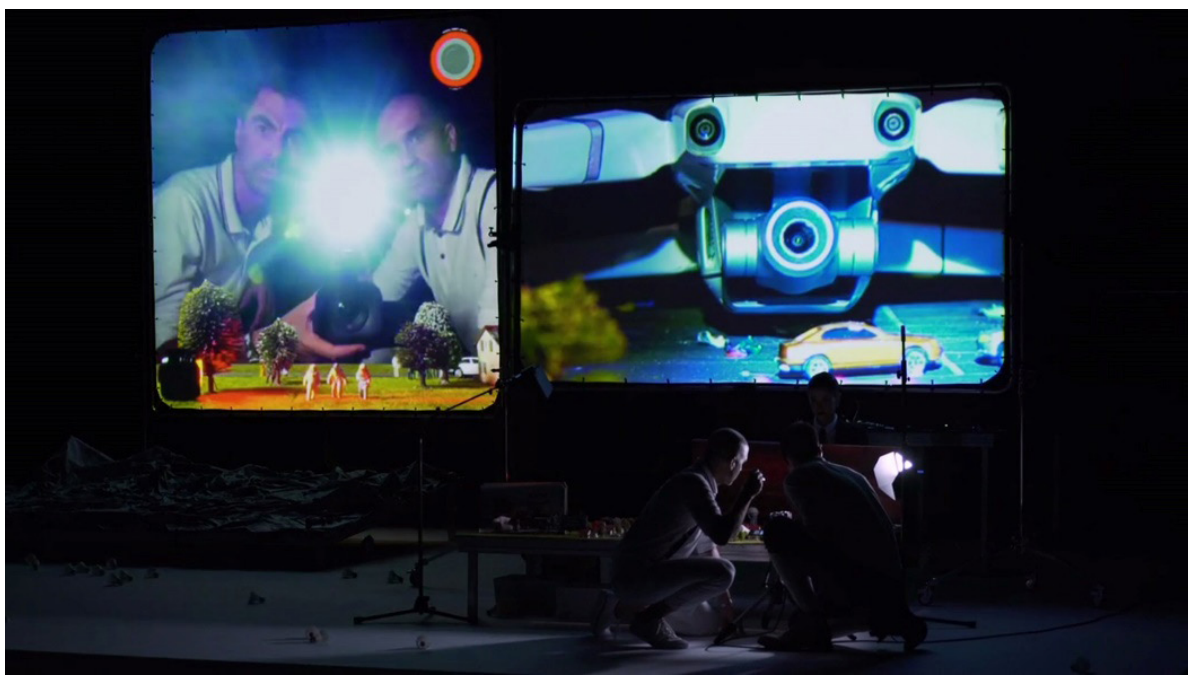

Figura 4. Simultaneidad entre dron-nave observador y manipuladores observados.

Fuente: Agrupación Señor Serrano.

Se produce otra simultaneidad cuando el dron recorre la maqueta de la ciudad, lo cual se muestra en las pantalla central y derecha, mientras que la izquierda presenta insertos de Tom Cruise huyendo en La guerra de los mundos alternados con fotogramas de Welles. También aparece en la expedición al Everest, donde las pantallas izquierda y central presentan la maqueta montańosa de la izquierda mientras que en la pantalla derecha se ven imágenes documentales y luego en la izquierda insertos como Moisés con las Tablas de la Ley en Los diez mandamientos (1956) o Gandalf en la montaña en La comunidad del anillo (2001). 


\subsection{Recontextualización}

Como las maquetas, la escala performativa puede emular un set cinematográfico que, a ojos de la cámara, pueda parecer una escena en entorno totalmente definido, mientras que para el público se evidencia su composición con pocos elementos en escena. Es decir, el público observa cómo los actantes construyen un entorno ficcional que el plano audiovisual parece completo y autónomo.

Es utilizado cuando aparece la performer como Ruth escribiendo una de las cartas a Mallory y fumando. De fondo hay una cortina, que vemos colgada de una de las pantallas, desde la que se ha fundido para iniciar esta escena. El plano de cámara no permite ver toda la cara de la performer, mientras que la mesa limita la visibilidad a su torso. El recurso cinematográfico y pictórico de mostrar una parte de algo para dejar que el observador intuya el resto funciona haciendo que la imaginación termine la construcción del contexto en que dicha situación está sucediendo. Implica una ampliación metafórica donde predomina la videoescena por composición espacial, si bien el público accede a la vez la realización escénica de aquello recogido por la cámara, de modo que duplica la percepción. La ampliación de visibilidad implícita supone hacer visibles elementos que por su tamaño o posición resultarían poco o nada visibles, lo que puede generar atracción y sorpresa. A su vez, el punto de vista varía: la performer está inclinada sobre la mesa de la derecha y la cámara en su perpendicular, mientras que la videoescena muestra un plano frontal en la pantalla central. Este efecto multiplica la percepción de un mismo evento mediada como en vivo. 
Este recurso también se observa cuando llegada la última cota del Everest, en la mesa de la izquierda Palacios ata una bota a un crampón, el herraje para andar sobre la nieve. La bota está sujeta a una pierna de maniquí, pero en videoescena el plano detalle cerrado hace parecer en que se la está atando una persona.

También tiene lugar en el final con la mano cubriéndose de nieve emulando a la de George Mallory perdida en el Everest. El público ve cómo la mano del performer se cubre de nieve artificial, sin embargo, en la proyección que, en este caso, ocupa toda la escena, aparece un plano detalle como un cadáver enterrado en la nieve.

\subsection{Narración textual}

La función narrativa es mayoritaria en la videoescena de Agrupación Señor Serrano, ya sea por medio de imágenes, de vídeo o, en este caso, de texto. Como en casos anteriores como el subtitulado del Marco Antonio de Marlon Brando en Julio César de $B B B B$, que creaba para el espectáculo otro texto sutilmente diferente del dicho por el actor, en The Mountain leemos la narración de cómo la compañía creó una web de noticias ficticias que empezó a gozar de enorme popularidad. Lo hacemos sobre una canción rusa supuestamente emitida por radio, a modo de falsos subtítulos. El habitual humor mordaz de la compañía está presente a lo largo de todo el texto, en el que dicen haber publicado algunas noticias reales, luego algunas falsas progresivamente, promocionadas mediante perfiles falsos en redes sociales. 
El texto, apoyado por una música de tono amable y motivador, presenta una falsa historia que bien podría ser cierta, dado que los mecanismos de difusión a los que alude son plenamente reales. Agrupación Señor Serrano suele decir a este respecto: «no hacemos un teatro documental, sino un teatro muy documentado» (Segovia y Rod, 2018).

Esta función implica una ampliación metafórica muy sutil y cercana al zapping, pues el texto parece aludir a la canción, aunque no sea así, y es puntualmente ilustrado con imágenes.

\subsection{Collage manual}

Uno de los recursos que utiliza Agrupación Señor Serrano es frecuente en historias de viajes literarias o cinematográficas. Consiste en mostrar la ruta sobre un mapa por medio de la superposición de cartelitos y el trazado de líneas, cosa que aquí realizan para contar el ascenso a la cara norte del Everest. Alternan el collage con imágenes documentales, ampliación visual en plano detalle e insertos cinematográficos, todo ello acompañado de voz en off y música. Se produce una ampliación metafórica en la composición que se muestra en papel, visible al público gracias a su captura por la cámara, y con preeminencia total respecto de la acción escénica por su visibilidad y carácter informativo.

Habitualmente compone una imagen dinámica que explica partes de la narración. La compañía empleó una técnica similar en Birdie para explicar sobre una imagen capturada las líneas de su composición y la divina proporción. 


\subsection{Textura escenográfica}

Esta función de la videoescena implica la aportación del vídeo de características propias de la escenografía, aprovechando la potencialidad de las tecnologías de creación y edición. The Mountain la utiliza para proyectar nieve sobre todo el escenario al final del espectáculo, momento en que se infla por sorpresa una montaña en la plataforma central.

La textura ofrece un carácter visual si es plana o táctil si tiene relieve (Martínez Valderas, 2017, 16). En el caso de la videoescena, cualquier textura es obviamente visual, pero puede asimilar la profundidad de lo táctil. La nieve genera este efecto por su movimiento homogéneo y alto contraste, de tal forma que profundiza en la metáfora entre nieve e interferencia, asociada al contexto de la información que el espectáculo ha estado construyendo. Este recurso solía ser empleado por Svoboda y fue uno de los primeros que, junto las imágenes documentales, aparecieron en la historia de la videoescena por su facilidad de uso y apariencia. Se acerca a la multimedialidad por su sustitución o enlace con un elemento de otro campo significante.

En este caso no cubre solo las pantallas o algunos elementos seleccionados, sino que lo hace con toda la escena, por lo que se está buscando una atmósfera global, donde lo único que varía es el espontáneo crecimiento de la montaña central. Se podría decir que la metáfora se extiende por toda la visualidad del espectáculo. La información que ha dado es controversial, como el tema que trata. Todo es nieve, incluso la propia montaña solo es una ilusión hecha de aire. 


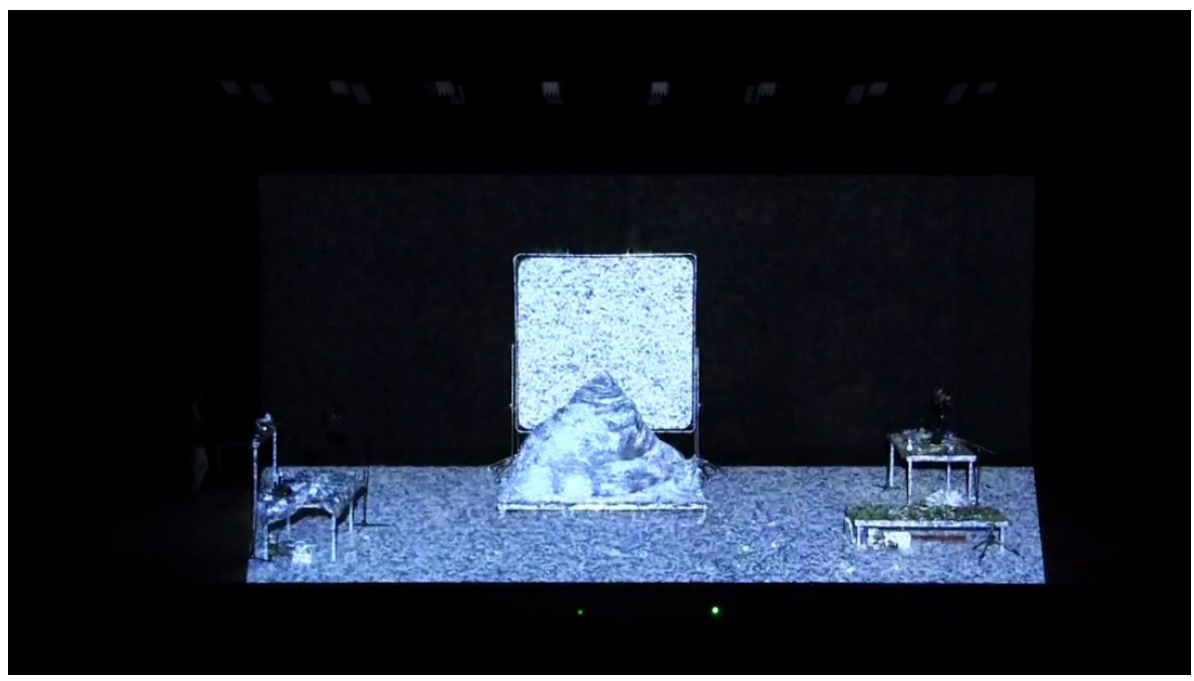

Figura 5: Textura videoescénica en todo el escenario.

Fuente: Agrupación Señor Serrano.

5. CONCLUSIONES: FUNCIONES DRAMATÚRGICAS DE LA VIDEOESCENA E INTERMEDIALIDAD

La dramaturgia de Agrupación Señor Serrano se basa en desarrollar el núcleo de convicción dramática mediante la videoescena. The Mountain, como espectáculos anteriores, emplea una estrategia estético-estilística presentacional para interpelar al público directamente, recurso evolucionado del distanciamiento brechtiano que, como este, provoca un extrañamiento respecto del estatus ficcional generador de una reflexión. Los recursos dramatúrgicos que se han estudiado se muestran dirigidos a tal fin, en especial, las de ampliación de visibilidad, el doble videoescénico, la multiplicación de puntos de vista, la recontextualización y la simultaneidad. La narración, en 
su multiplicidad y no linealidad, es esencial para comunicar el discurso, de ahí el carácter marcadamente narrativo de la metavideoescena, el collage o el propio texto. Por último, la sensorialidad abarca todo el espectáculo desde lo visual y lo sonoro, como se ve en la función atmosférica de la textura escenográfica. En conclusión, podría decirse a partir de la dramaturgia de la videoescena que el objetivo de la escenificación de The Mountain es que el espectador cuestione la veracidad de aquello que está viendo como metáfora de las certezas que asume en su vida habitual.

El espectáculo de la compañía catalana pone de manifiesto que la videoescena como parte del diseño escénico puede construir sólidamente aspectos dramatúrgicos del espectáculo, en diálogo con la acción escénica y coherencia con el resto de los elementos. Esta comunicación constante entre escena y videoescena genera una serie de efectos y sensaciones que no pueden construirse por medio de otros elementos teatrales, acaso sí emularse algunos de ellos. Por lo tanto, la existencia de una mayoría de usos intermediales de la videoescena implican que el espectáculo se encuentra en el extremo intermedial del espectro multimedia: el núcleo de convicción dramática se despliega a través del vídeo y el espectáculo solo puede efectuar la comunicación teatral apoyándose en él. Siguiendo a Fischer-Lichte: «La condición específica del medio influye esencialmente en el proceso de creación de significado y por eso debe considerarse como un factor constitutivo» $(1999,526)$. Es decir, en la dramaturgia del teatro intermedia, la forma del medio incorporado es indisoluble del contenido para el que se utiliza. 
Con estas consideraciones, se alcanzan los dos objetivos propuestos: el principal de analizar la dramaturgia de la videoescena en The Mountain de Agrupación Seńor Serrano y el secundario de demostrar la utilidad de la clasificación de funciones dramatúrgicas de la videoescena para la caracterización multimedial de un espectáculo teatral. Los recursos dramatúrgicos expuestos son, como se ha visto, difícilmente deslindables, pues aparecen a menudo solapados entre sí, no obstante, su análisis permite profundizar en el sentido del vídeo en el teatro. Esto reafirma su estatus como valioso elemento expresivo, siempre y cuando su funcionalidad se encuentre consolidada dentro de la dramaturgia espectacular.

\section{REFERENCIAS BIBLIOGRÁFICAS}

59 Productions. Forbidden zone. 2014. Disponível em: <https://59productions. co.uk/project/forbidden-zone/>. Acesso em: 10 jan. 2020.

Abellán, Joan. "El teatro visual". In: Sánchez, José Antonio (coord.). Artes de la escena y de la acción en España: 1978-2002, Cuenca: UCLM, 2006, 103-118.

Abuín González, Anxo "Teatro y nuevas tecnologías: conceptos básicos". In: Signa, 17, 2008, 29-56.

Bolter, Jay David y Grusin, Robert. Remediation: Understanding new media. Cambridge, Massachusetts: MIT Press, 2000.

Burian, Jarka M. "Josef Svoboda: Theatre Artist in an Age of Science". In: Education Theatre Journal, 22 (2), 1970, 123-145.

Cornago Bernal, Óscar. "El cuerpo invisible: teatro y tecnologías de la imagen". In: Arbor, CLXXVII, 699-700, 2004, 595-610. 
Recursos videoescénicos en la dramaturgia intermedial. Análisis de The Mountain de Agrupación Señor Serrano

Fischer-Lichte, Erika. Semiótica del teatro (E. Briega, trad.). Madrid: Arco Libros, 1999.

Giannachi, Gabriella. Virtual theatres: an introduction. Oxon: Routledge, 2004.

Giesekam, Greg. Staging the screen. Basingtoke: Palgrave Macmillan, 2007.

Grande Rosales, María Ángeles. "Mundos que se desvanecen. Tecnoteatros y performatividad". In: Caracteres. Estudios culturales y críticos de la esfera digital, 4 (2), 2015, 8-17.

Hartwing, Susan. "Descentralización visual: la escena fragmentada del teatro español contemporáneo”. In: Bulletin of Hispanic Studies, 81 (1), 2004, 43-53.

Hormigón, Juan Antonio Trabajo dramatúrgico y puesta en escena, vol. I. Madrid: Publicaciones de la ADE, 2002, 2a ed.

Iglesias Simón, Pablo. “Una conversación con Robert Lepage a la hora del té”. In: ADE-Teatro, 106, 2005, 74-82.

Iglesias Simón, Pablo. “Tecnofilias y tecnofobias”. In: ADE-Teatro, 109, 2006, 49-53.

Kattenbelt, Chiel. "Intermediality in Theatre and Performance: Definitions, Perceptions and Medial Relationships". In: Cultura, lenguaje y representación, VI, 2008, 19-29.

Lehmann, Hans-Thies. Teatro posdramático (D. González, trad.). Murcia: Centro de Artes Contemporáneas, 2013.

López Antuñano, José Gabriel. "Teatro: cine, imagen o palabra”. In: ADE-Teatro, 138, 2011, 139-145.

López Antuñano, José Gabriel. "Presentación versus representación”. In: Nueva revista, 140, 2012, 172-187.

López Antuñano, José Gabriel. "Teatro multimedia: antecedentes y estado de la cuestión”. In: Nueva revista, 148, 2014, 168-183.

Luna, Álvaro. "Videoescena, el intruso transversal". In: ADE-Teatro, 161, 2016, 113-118. 
Magris, Erica. "Between Empathy and Dissection: the live cinema by Katie Mitchell”. In: Revista Brasileira de Estudos da Presença, 6 (2), 2016, 186-205.

MandragoraBCN. Agrupación Señor Serrano. 16 nov. 2016. Disponível em: <https:// youtu.be/gf4wZavBbNI>. Acesso em: 10 jan. 2020.

Martínez, David. "Videoescena en la Dirección Escénica (I)”. In: ADE-Teatro, 173, 2018, 173-181.

Martínez Valderas, Jara. Manual de espacio escénico. Terminología, fundamentos y proceso creativo. Granada: Tragacanto, 2017.

Pavis, Patrice. El análisis de los espectáculos: teatro, mimo, danza, cine. Barcelona: Paidós, 2000.

Piscator, Erwin. Teatro político (S. Vila, trad.). Madrid: Ayuso, 1976.

Segovia, Ángela y Rod, Carlos. Una conversación con Àlex Serrano. 2018. Disponível em: <https://www.teatroscanal.com/espectaculo/agrupacion-senor-serrano/>. Acesso em: 10 jan. 2020.

Teatro a mil. Clase Magistral: Viviendo del fracaso | Agrupación Señor Serrano. 30 jul. 2018. Disponível em: <https://youtu.be/0ZgecG6h04Q>. Acesso em: 10 jan. 2020.

Teira Alcaraz, José Manuel. "El audiovisual en escena: del teatro multimedia al teatro intermedia a través de la videoescena". In: Actio Nova, 4, 2020a, 129-165.

Teira Alcaraz, José Manuel "Hacia un análisis de la función dramatúrgica de la videoescena”. In: Acotaciones, 45, 2020b, 291-322.

Teira Alcaraz, José Manuel "La crítica social de Agrupación Señor Serrano a través de la dramaturgia intermedial. Entrevista a Pau Palacios". In: Anagnórisis, 22, 2020c, 467-484.

Thenon, Luis "El cartero de Londres". In: ADE-Teatro, 106, 2005, 85-96. 